\title{
INNOVATION OF TRAINING DESIGN TO INCREASE WRITING SKILL OF SCIENTIFIC ARTICLES FOR PARTICULAR FUNCTIONAL CIVIL SERVANTS THROUGH THE "REVERSE THINKING” METHOD
}

\author{
Endan Suwandana \\ BPSDMD Provinsi Banten, Indonesia \\ endan2006@yahoo.com
}

\begin{abstract}
This study aims at creating, implementing dan examining a training design innovation, whether or not it can improve the ability of the trainees. The study was carried out using descriptive-quantitative approach. This study has successfully created a training design called the Reverse Thinking (RT) method. That training design was then applied to the Article Writing Training at the Education and Training Center of the Central Statistics Bureau, attended by widyaiswara and statisticians with a total of 95 participants divided into two batches. The RT method has proven to be very effective in improving the ability of trainees to write scientific articles, both in terms of cognitive, affective, and psychomotoric (practical) aspects. Some indicators were that almost $100 \%$ of the trainees successfully submitted their papers to scientific journals on the last day of the training, evenmore 28 articles finally being published. The cognitive abilities of the participants also improved, indicated by the increase of the post-test scores. In the affective aspect, all participants have stated that their motivation in writing articles increased, as shown by the concentrated value between 7 and 10, from the $1-10$ Likert Scale. Those results proved that the RT method could effectively improve competence of the training participants, both teoritically and practically.
\end{abstract}

Keywords: BPS training center, JFT, KTI training, learning method innovation, statistician, widyaiswara

\section{INOVASI DESAIN PELATIHAN UNTUK MENINGKATKAN KEMAMPUAN MENULIS ARTIKEL ILMIAH BAGI JABATAN FUNGSIONAL TERTENTU MELALUI METODE "BERPIKIR TERBALIK"}

\begin{abstract}
ABSTRAK
Kajian ini bertujuan untuk menciptakan, menerapkan, dan menguji sebuah inovasi desain pelatihan apakah dengan metode ini mampu meningkatkan kemampuan peserta pelatihan. Kajian ini dilakukan dengan menggunakan pendekatan deskriptif kuantitatif. Penelitian ini berhasil menciptakan sebuah disain pelatihan yang diberi nama metode Reverse Thinking (RT). Disain pelatihan ini diterapkan pada Pelatihan Penulisan Artikel Ilmiah di Pusdiklat BPS yang diikuti oleh widyaiswara dan statistisi dengan total peserta 95 orang terbagi dalam dua angkatan. Metode RT terbukti sangat efektif dalam meningkatkan kemampuan peserta, baik dari aspek kognitif, afektif, dan psikomotorik (praktik). Indikatornya adalah bahwa hampir $100 \%$ peserta pelatihan berhasil mengirimkan naskah papernya ke jurnal ilmiah pada hari terakhir pelatihan, bahkan 32 artikel pada akhirnya berhasil terbit. Kemampuan kognitif peserta pun meningkat yang diindikasikan dari nilai post-test. Pada aspek afektif, seluruh peserta menyatakan meningkat motivasinya dalam menulis artikel yang ditunjukkan dengan nilai yang terpusat pada 7 dan 10, dari skala Likert 1 - 10. Dengan hasil tersebut, desain pelatihan dengan metode berpikir terbalik terbukti mampu secara efektif meningkatkan kemampuan peserta pelatihan, baik secara teori maupun praktik.
\end{abstract}

Kata Kunci: Diklat KTI, inovasi metode pembelajaran, JFT, Pusdiklat BPS, statistisi, widyaiswara

\begin{tabular}{|c|c|c|}
\hline Submitted & Accepted & Published \\
\hline 06 Januari 2020 & 07 Juli 2020 & 25 Juli 2020 \\
\hline
\end{tabular}

\begin{tabular}{|l|l|c|}
\hline Citation & $:$ & $\begin{array}{c}\text { Suwandana, E. (2020). Innovation of Training Design to Increase Writing Skill of Scientific Articles for Particular } \\
\text { Functional Civil Servants through the "Reverse Thinking" Method. Jurnal PAJAR (Pendidikan dan } \\
\text { Pengajaran), 4(4), 828-842. DOI : http://dx.doi.org/10.33578/pjr.v4i2.7947. }\end{array}$ \\
\hline
\end{tabular}




\section{PENDAHULUAN}

Menurut Elfindri dkk (2015), jumlah publikasi ilmiah di Indonesia masih sangat rendah. Begitu pula menurut Wiryawan (2014), jumlah jurnal ilmiah baik yang telah terakreditasi nasional, maupun yang telah diakui internasional masih sangat rendah. Saat ini Indonesia memang berada pada peringkat kedua di ASEAN dalam hal jumlah publikasi ilmiah, yaitu sebanyak 5125 paper melebihi Singapura yang hanya memiliki 2948 paper (risbang.ristekdikti.go.id), namun kualitas publikasi imliah Indonesia tersebut masih belum maksimal (mediaindonesia.com).

Sumbangsih jumlah publikasi ilmiah itu bukan hanya diberikan oleh para dosen, peneliti, dan perekayasa saja, melainkan juga oleh seluruh jabatan fungsional tertentu (JFT) di Indonesia, seperti widyaiswara, statistisi, guru, penyuluh, auditor, perencana, analis kebijakan, dan sebagainya. Sementara itu, menurut situs id.wikipedia.com (diakses 2 Januari 2020), sampai dengan Bulan Januari 2020, terdapat 200 jenis JFT di Indonesia. Dapat dipastikan bahwa semua jenis JFT tersebut memiliki kewajiban untuk menulis karya tulis ilmiah (KTI).

Namun demikian bagi sebagian mahasiswa, dosen, peneliti dan insan akademis lainnya, menulis paper ilmiah masih merupakan suatu pekerjaan yang sulit dan membutuhkan keahlian khusus (Indarti, 2012; Madjid, dkk., 2017). Padahal kemampuan menulis paper ini selain dapat dapat membantu para JFT dalam pengumpulan angka kredit dan kenaikan pangkat, juga bermanfaat untuk mendiseminasikan hasilhasil penelitian dan karya ilmiah lainnya.

Untuk mengatasi hal tersebut, maka diperlukan sebuah upaya inovatif yang dapat meningkatkan kemampuan para JFT dalam menyusun artikel ilmiah secara efektif. Menurut Madjid dkk (2017) dan Wischgoll (2017), salah satu upaya yang dapat dilakukan adalah melalui kegiatan pelatihan. Saat ini telah banyak sekali upaya yang dilakukan oleh berbagai pihak dalam meningkatkan kemampuan menulis para JFT dan insan akademis lainnya. Beberapa pelatihan menulis paper di antaranya pernah dilakukan di kalangan mahasiswa (Ananta dkk, 2016), guru
(Redhana dkk, 2014), dosen (Ginanjar, 2018), serta widyaiswara (Arthur, 2018).

Sayangnya, beberapa pelatihan tersebut tidak terfokus pada kemampuan praktis (praktik menulis paper). Sehingga pasca pelatihan, tidak jarang para alumni masih saja kesulitan dalam memulai tulisan, mencari ide, menyusun tulisan dan menerbitkannya. Akibatnya kemampuan menulis artikel ilmiah para peserta pelatihan pun tidak meningkat secara signifikan.

Sebagian pelatihan penulisan artikel ilmiah malah hanya terfokus pada evaluasi penyelenggaraan pelatihannya dan/atau evaluasi terhadap narasumbernya saja, seperti yang dilakukan oleh Arthur (2018), dan Ginanjar (2018). Sebagian pelatihan lain hanya terfokus pada peningkatan pengetahuan kognitifnya saja yang diukur dari nilai pre-test dan post-test, seperti yang dilakukan oleh Ananta dkk (2016). Sebagian pelatihan lain hanya terfokus pada peningkatan aspek afektif (motivasi) saja, seperti yang dilakukan oleh Redhana dkk (2014).

Berdasarkan latar belakang di atas, maka dirasakan sangat perlu untuk menciptakan sebuah terobosan (breakthrough) berupa inovasi metode pelatihan yang didisain sedemikian rupa agar pada akhir pelatihan setiap peserta mampu melakukan pengiriman naskah paper ke jurnal ilmiah, khususnya jurnal ilmiah nasional terakreditasi. Di samping itu, pelatihan itu pun harus didisain sedemikian rupa agar stigma yang ada selama ini yang mengatakan bahwa menulis paper itu sulit dan lama berubah menjadi mudah, cepat, dan menyenangkan.

Inovasi-inovasi metode pembelajaran perlu terus dilakukan agar hasil pembelajaran dapat lebih berkualitas (Indarti, 2012), karena kejumudan dalam metode pembelajaran dapat menciptakan kebosanan dan stagnasi dalam kualitas kemampuan praktis peserta diklat. Bahkan menurut Gutiérrez dan Villegas (2015), metode pembelajaran yang salah justru dapat membuat peserta tidak atraktif terhadap proses pembelajaran.

Untuk itulah maka kajian yang bersifat penelitian percobaan (experiental research) ini dilakukan. Ada dua hal yang melandasi dilakukannya kajian ini, yaitu untuk: 1) 
Menciptakan sebuah inovasi disain pelatihan yang dapat membantu peserta pelatihan secara cepat dan produktif dalam menulis artikel ilmiah. Pelatihan itu didisain sedemikian rupa, dimana pada akhir pelatihan seluruh peserta mampu mengirimkan naskah papernya ke jurnal ilmiah; 2) Mengkaji

\section{KAJIAN TEORETIS Pelatihan}

Pelatihan adalah cara yang dianggap paling efektif untuk meningkatkan kemampuan menulis (writing skills) para peserta pelatihan (Madjid dkk, 2017 dan Wischgoll, 2017). Menurut Swanson dan Holton (2001) pelatihan harus didisain secara sistematis agar dapat meningkatkan pengetahuan dan keahlian peserta pelatihan yang pada akhirnya dapat meningkatkan performa para alumni pelatihan pada instansi dimana mereka bekerja.

Sayangnya, pelatihan acapkali dianggap sebagai aktivitas yang sepele, padahal pelatihan memerlukan disain dan perencaaan yang serius dan matang. Bahkan perencanaan dan disain pelatihan itu sendiri menjadi aktivitas utama yang biasanya membutuhkan alokasi waktu dan tenaga yang lebih banyak daripada pelaksanaan pelatihannya itu sendiri. Misalnya, menurut Rohaeni dan Jubaedah (2010), jika pelaksanaan pelatihan dilaksanakan tiga hari, maka persiapannya bisa menghabiskan 10-15 hari sebelum pelatihan dimulai. Selain perencanaan dan disain, pelatihan juga tergantung pada motivasi, sikap (attitude), dan kecerdasan emosi (emotional intelligence) dari para penyelenggara dan manajer pelatihannya (Punia dan Kant, 2013).

\section{Disain Pelatihan}

Salah satu faktor kunci yang mempengaruhi keberhasilan suatu kegiatan belajarmengajar atau pelatihan adalah metode pembelajaran (teaching methods), sebagaimana dinyatakan oleh Khales (2016), dan Kant (2013), serta Punia Kremer dan Perlberg (2006). Metode pembelajaran yang usang (out-of-date) dan tidak menarik akan berpengaruh pada motivasi peserta dan capaian hasil yang diharapkan. apakah disain pelatihan yang diciptakan itu dapat meningkatkan kemampuan peserta pelatihan secara efektif, baik dari sisi kognitif, afektif, dan psikomotorik (praktik) dengan indikator utama adalah peserta berhasil mengirimkan artikelnya ke jurnal ilmiah sampai berhasil dipublikasikan.

Menurut Yaqoot dkk (2017), keberhasilan pelatihan tergantung pada lingkungan pelatihan dan efektifitas pelatihan, termasuk di antaranya menyangkut program pelatihan, gaya mengajar narasumber, serta kelengkapan alat dan materi pelatihan. Hajjar dan Alkhanaizi (2018) menyatakan ada lima faktor yang mempengaruhi efektifitas pelatihan, yaitu isi materi pelatihan (training contents), gaya presentasi (presentation styles), jadwal pelatihan (training schedule), sarana dan bahan pelatihan (facilities \& materials), serta lingkungan atau suasana pelatihan (training environment).

Disain pelatihan benar-benar menjadi faktor penentu dalam menentukan kualitas hasil pelatihan. Pentingnya disain pelatihan dalam sebuah pelatihan telah digambarkan setidaknya oleh Al-Omrani (2014), Velada dkk (2007), dan Lim (2006). Sebelumnya, Holton (2005) menyatakan bahwa para alumni pelatihan nampaknya akan dapat menerapkan hasil-hasil pelatihan, hanya jika program pelatihan itu telah didisain dan dilaksanakan sedemikian rupa sehingga benar-benar dirasakan mampu memaksimalkan kemampuan mereka.

Dalam konteks pelatihan penulisan artikel ilmiah, peserta tidak hanya dibekali materi tentang cara melakukan penelitian saja, melainkan lebih jauh harus dibekali materi sekaligus praktik tentang bagaimana memulai menulis artikel ilmiah serta syarat-syarat dan rambu-rambu agar sebuah artikel ilmiah dapat dipublikasikan dalam jurnal ilmiah yang berkualitas. Arta (2018) menjelaskan bahwa materi yang diberikan dalam pelatihan KTI meliputi: etika penulisan, hakikat karya ilmiah, anatomi artikel ilmiah, dan komponen artikel ilmiah. 


\section{METODE PENELITIAN}

Penelitian ini merupakan penelitian percobaan (experiental research) dengan fokus penelitian pada JFT widyaiswara dan statistisi. Penelitian ini dilakukan dengan menggunakan pendekatan deskriptif kuantitatif dengan studi kasus pada pelatihan penulisan artikel ilmiah di Pusat Pendidikan dan Pelatihan - Badan Pusat Statistik (Pusdiklat BPS).

Penelitian ini dilakukan melalui dua angkatan Pelatihan Penulisan KTI (Batch 1 dan Batch 2) yang dilaksanakan di Pusdiklat BPS RI yang berlokasi di Jalan Raya Jagakarsa No. 70, Lenteng Agung, Jakarta. Masing-masing angkatan (batch) dilaksanakan selama empat hari. Pelatihan Batch 1 dilaksanakan pada tanggal 5-8 November 2018. Sedangkan Batch 2 dilaksanakan pada tanggal 21-24 November 2018. Jumlah peserta pada Batch 1 adalah 40 orang dan Batch 2 adalah 55 orang. Peserta pada Pelatihan Batch 1 merupakan pegawai BPS dari kelompok JFT widyaiswara (16 orang) dan JFT statistisi se-Pulau

\section{HASIL DAN PEMBAHASAN \\ Disain Inovasi Pelatihan}

Untuk mengatasi kesulitan dalam penyusunan KTI, kajian ini mencoba mengembangkan sebuah inovasi metode pelatihan penulisan artikel ilmiah yang diberi nama metode berpikir terbalik ata Reverse Thinking (RT). Inovasi metode pelatihan ini didasari oleh adanya stigma bahwa hambatan terbesar yang dialami oleh mayoritas orang dalam menulis paper adalah mencari ide/topik tulisan (Salamah dan Sumarsilah, 2018; Rahmiati, 2015). Mindset kita sudah terbentuk (framing) sejak lama bahwa menulis KTI atau artikel ilmiah itu harus dimulai dari mencari ide/topik tulisan, lalu dilanjutkan dengan menyusun pendahuluan, landasan teori, metodologi, hasil, pembahasan, dan kesimpulan.

Untuk melakukan perubahan mindset dan agar menjadi manusia yang lebih kreatif, Paul Arden dalam bukunya "Whatever You Think, Think the Opposite" menyarankan pentingnya untuk berpikir secara menyabang (lateral thinking), bukan berpikir linear (Arden, 2003). Selain dengan cara berpikir lateral, Covey (1989)
Jawa (24 orang). Sedangkan pada Batch 2, peserta seluruhnya merupakan pegawai BPS dari kelompok JFT statistisi se-Indonesia (selain Pulau Jawa) dengan jumlah 55 orang. Sehingga total peserta dari dua angkatan pelatihan KTI ini adalah 95 orang, yang semuanya menjadi responden penelitian.

Pada kajian ini, seluruh aspek penilaian peserta pelatihan diukur menggunakan kuesioner online dengan memanfaatkan fasilitas Google Form. Ada tiga jenis test / kuesioner, yaitu: 1) Preassessment test, 2) Pre-test dan Post-test, dan 3) Self-assessment test, dimana sebagiannya menggunakan penilaian Skala Likert $1-10$. Pemanfaatan Google Form untuk membantu pengambilan data penelitian juga dilakukan oleh banyak peneliti (Farmer, 2016; Batubara dan Ariani, 2016; Slamet, 2016). Dengan menggunakan aplikasi ini, hasil dari tes atau kuesioner dapat dilihat dengan cepat pada saat itu juga (real time) oleh seluruh peserta.

juga menambahkan pentingnya untuk berpikir dari bagian akhir (begin with the end in mind), karena ini adalah salah satu kebiasaan dari orang-orang yang sangat efektif dan sukses. Berdasarkan konsep berpikir lateral dan berpikir dari bagian akhir inilah maka kajian ini dilakukan.

Pelatihan ini didisain selama empat hari dengan sebuah target bahwa pada hari terakhir pelatihan seluruh peserta diharapkan sudah mampu melakukan pengiriman naskah artikel ke jurnal ilmiah. Secara rinci, alur metode RT ini terdiri dari 17 langkah, yaitu: 1) melakukan pencarian data, 2) melakukan analisis data, 3) menuliskan hasil analisis, 4) melakukan diskusi dan pembahasan, 5) menulis kesimpulan, 6) menyusun metodologi, 7) menulis pendahuluan, 8) menulis abstrak, 9) merumuskan judul, 10) memberikan sitasi, 11) menuliskan daftar pustaka, 12) memeriksa plagiarisme, 13) mencari jurnal ilmiah, 14) melakukan registrasi ke jurnal ilmiah, 15) menyesuaikan naskah paper menurut gaya selingkung, RT16) melakukan proof-reading, dan 17) mengirimkan naskah paper ke jurnal ilmiah. 
Inilah inovasi disain pelatihan penulisan artikel ilmiah yang dikembangkan dan telah diterapkan di beberapa tempat. Metode RT berhasil berubah mindset peserta pelatihan karena dengan metode ini peserta pelatihan mampu melakukan penulisan KTI bukan dari mencari judul dan menulis pendahuluan, tapi bahkan memulainya dari mengolah data dan menuliskan hasil sebagaimana diilustrasikan oleh Gambar 1.

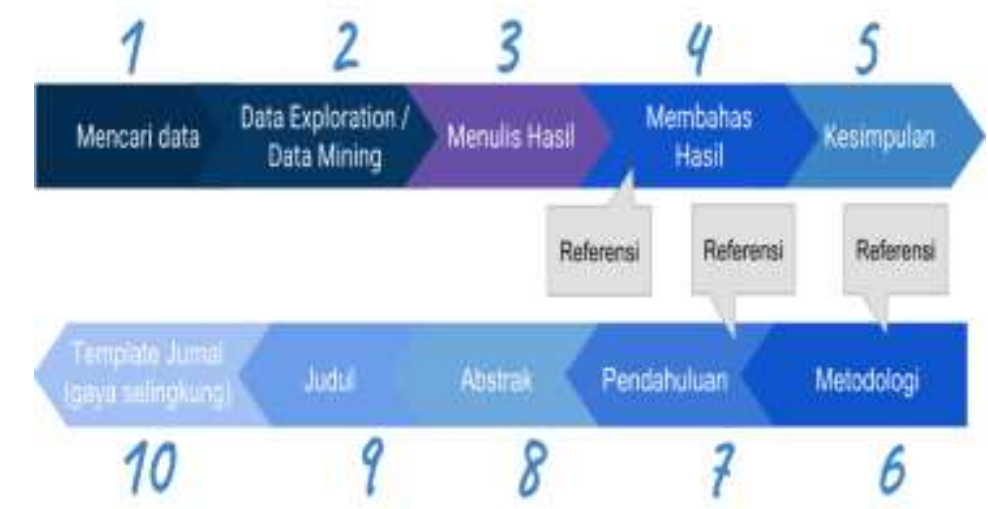

Gambar 1. Alur penulisan artikel ilmiah dengan metode Reverse Thinking (RT).

Teknik menulis paper yang dimuilai dari pengolahan data ini juga direkomendasikan oleh para ahli di researchgate.com (2018). Begitu juga Hoogenboom and Manske (2012) yang menyukai menulis paper dimulai dari menuliskan hasil, lalu pendahuluan dan diskusi. Jenkins (1995) pun menyarankan menulis paper dari metodologi dan hasil, lalu pembahasan, kesimpulan, pendahuluan, daftar pustaka, judul, dan terakhir abstrak.

\section{Evaluasi Penerapan Disain Pelatihan}

Tabel 1. Daftar pelatihan penulisan artikel ilmiah yang telah menerapkan metode Reverse Thinking di beberapa lokasi pelatihan di Indonesia.

\begin{tabular}{|c|c|c|c|}
\hline No & Tanggal & Lokasi & $\begin{array}{c}\text { Peserta berdasarkan } \\
\text { Jenis JFT } \\
\end{array}$ \\
\hline 1 & $\begin{array}{l}\text { 05-08 Nov } \\
2018\end{array}$ & $\begin{array}{l}\text { Pusdiklat BPS RI, } \\
\text { Jakarta (Batch 1) }\end{array}$ & Widyaiswara, Statistisi (40 orang) \\
\hline 2 & $\begin{array}{l}21-24 \text { Nov } \\
2018\end{array}$ & $\begin{array}{l}\text { Pusdiklat BPS RI, } \\
\text { Jakarta (Batch 2) }\end{array}$ & Statistisi (55 orang) \\
\hline 3 & 12-15 Feb 2019 & BPSDMD Prov. Papua & $\begin{array}{l}\text { Widyaiswara ( } 40 \text { orang) } \\
\text { Peneliti, Perencana, Pengawas Sekolah, Polisi }\end{array}$ \\
\hline 4 & $\begin{array}{l}11-14 \text { Mar } \\
2019\end{array}$ & $\begin{array}{l}\text { BPSDMD Prov. Bangka } \\
\text { Belitung }\end{array}$ & $\begin{array}{l}\text { Hutan, Penyelidik Bumi, Guru, Pranata Humas, } \\
\text { Pengawas Mutu Hasil Pertanian, Analis } \\
\text { Kebijakan, Instruktur, P2UPD (40 orang) }\end{array}$ \\
\hline 5 & 24-27 Jun 2019 & $\begin{array}{l}\text { BPSDMD Prov. } \\
\text { Sumatera Selatan } \\
\text { Pusdiklat Tenaga }\end{array}$ & $\begin{array}{l}\text { Widyaiswara, Peneliti, Perencana, Pengawas } \\
\text { Sekolah ( } 40 \text { orang) }\end{array}$ \\
\hline 6 & $\begin{array}{l}\text { 05-08 Agu } \\
2019\end{array}$ & $\begin{array}{l}\text { Administrasi } \\
\text { Kementerian Agama, } \\
\text { Ciputat }\end{array}$ & $\begin{array}{l}\text { Widyaiswara, Peneliti, Arsiparis, Auditor ( } 40 \\
\text { orang) }\end{array}$ \\
\hline 7 & 03-07 Sep 2019 & $\begin{array}{l}\text { Bappeda Provinsi } \\
\text { Sumatera Selatan }\end{array}$ & Perencana dan Peneliti (40 orang) \\
\hline
\end{tabular}




\begin{tabular}{llll}
\hline 8 & $22-24$ Okt 2018 & $\begin{array}{l}\text { BKPSDM Kota } \\
\text { Tangerang }\end{array}$ & Guru SD dan Guru SMP (30 orang) \\
\hline
\end{tabular}

Sejak pertama kali diciptakan pada pertengahan tahun 2018, metode RT ini sudah diimplementasikan di beberapa pelatihan penulisan artikel ilmiah di Indonesia. Implementasi ini diperlukan untuk membuktikan apakah metode ini dapat meningkatkan kemampuan menulis artikel ilmiah secara cepat dan efektif. Tabel 1 merinci daftar pelatihanpelatihan penulisan artikel ilmiah dimana metode RT telah diterapkan.

Namun demikian, untuk kepentingan penelitian ini hanya pelatihan yang dilaksanakan di Pusdiklat BPS sajalah yang dianalisis. Hal ini dikarenakan kedua pelatihan tersebut (Batch 1 dan Batch 2) dilaksanakan lebih awal (November 2018), yaitu sekitar delapan bulan yang lalu. Waktu delapan bulan ini telah dianggap cukup untuk dapat dilakukan evaluasi terhadap alumni pelatihan, mengingat periode penerimaan artikel dari mulai dikirimkan sampai dengan diterima oleh mitra bestari (reviewer) dan editor sampai diterbitkan oleh jurnal biasanya memakan waktu sekitar 2-12 bulan, atau bahkan lebih.

\section{Survei Kondisi Peserta Sebelum Pelatihan}

Hasil pre-assessment test menunjukkan bahwa untuk Batch 1, sebanyak $67.6 \%$ peserta mengaku sama sekali belum pernah menulis paper di jurnal manapun. Sedangkan pada Batch 2 kondisi itu lebih tinggi lagi, yaitu sebanyak $72.7 \%$. Sementara sisanya bervariasi menyatakan pernah memiliki pengalaman menulis pada berbagai level jurnal ilmiah (Gambar 2).

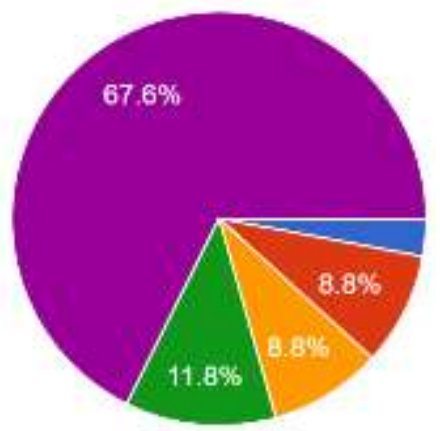

Batch 1

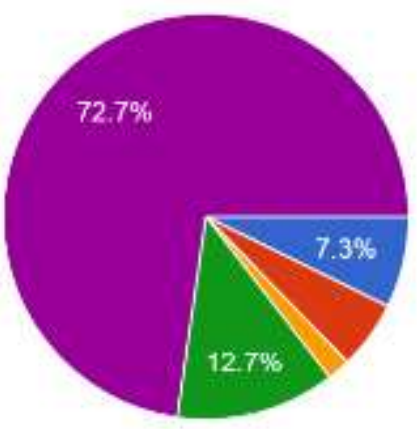

Batch 2

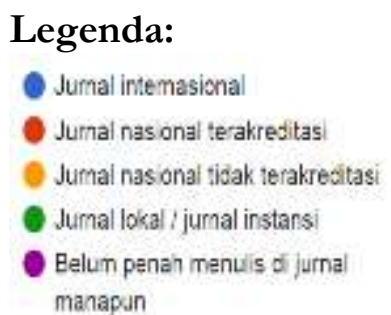

Gambar 2. Hasil Pre-Assessment Test dari Calon Peserta Pelatihan Penulisan Artikel Ilmiah
Kondisi awal peserta yang tergambarkan melalui Gambar 2 merupakan sebuah kondisi yang cukup ideal untuk menerapkan metode RT, karena masih banyak calon peserta yang sama sekali belum memiliki pengalaman dalam menulis artikel ilmiah. Realitas kondisi ini merupakan starting point yang baik untuk menguji apakah metode RT ini terbukti mampu meningkatkan kemampuan peserta pelatihan dalam menulis artikel ilmiah.

Hasil pre-assessment test menunjukkan bahwa para calon peserta memiliki persepsi yang berbeda-beda tentang kesulitan dalam menulis artikel ilmiah (Gambar 3). Pada Batch 1, lebih dari 25\% calon peserta pelatihan menyatakan bahwa hambatan yang sering dihadapi ketika hendak menulis paper adalah "tidak tahu harus memulai dari mana". Lebih dari $25 \%$ lainnya menyatakan tidak tahu kriteria paper yang layak terbit pada jurnal ilmiah. Lebih dari $25 \%$ lainnya tidak menguasai metode analisis statistik. Sementara $25 \%$ sisanya menjawab dengan alasan yang beragam.

Pada Batch 2, hampir setengah dari jumlah calon peserta pelatihan mengaku bahwa 
mereka "tidak tahu harus memulai dari mana". Lalu, 35\% calon peserta mengaku sulit mencari ide/topik tulisan, dan sebagian peserta lainnya memberikan jawaban bervariasi. Kondisi riil peserta seperti ini pun menjadi awal yang cukup menantang untuk membuktikan bahwa metode RT sangat efektif meningkatkan kemampuan dalam menulis artikel ilmiah.

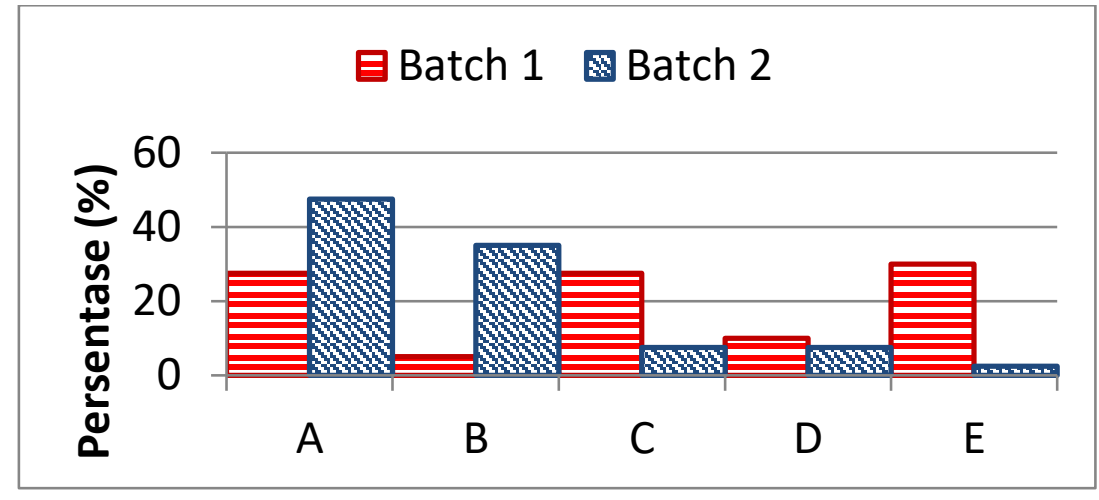

Keterangan:

$\mathrm{A}=$ Tidak tahu harus memulai dari mana

$\mathrm{B}=$ Sulit mencari ide / topik tulisan

Tidak tahu kriteria paper yang layak terbit pada

$\mathrm{C}=$ jurnal ilmiah

Tidak tahu cara mencari jurnal ilmiah dan

$\mathrm{D}=$ mengirimkan paper ke jurnal tersebut

$\mathrm{E}=$ Tidak menguasai metode analisis statistik

Gambar 3. Hasil Pre-Assessment Test dari Calon Peserta Pelatihan Penulisan Artikel Ilmiah

\section{Peningkatan Kemampuan Kognitif}

Setelah pelatihan berakhir, peserta pelatihan penulisan artikel ilmiah di Pusdiklat BPS menunjukkan peningkatan kemampuan pengetahuan (kognitif) yang cukup baik (Gambar 4). Hal itu ditunjukkan oleh meningkatnya nilai post-test dibandingkan dengan nilai pre-test. Pada Batch 1 telah terjadi peningkatan nilai rata-rata kelas dari hanya 54.61 (median 55 dan SD \pm
10.62) menjadi 76.75 (median 75 dan $\mathrm{SD} \pm 9.91$ ). Nilai minimum dan maksimum pada saat pre-test masing-masing adalah 35 dan 80, serta 45 dan 95 pada saat post-test. Hasil ini menunjukkan pengetahuan para peserta pelatihan mengenai konsep dan teori artikel ilmiah, jurnal ilmiah, serta ketentuan-ketentuan yang terkait dengannya meningkat dengan cukup baik. 


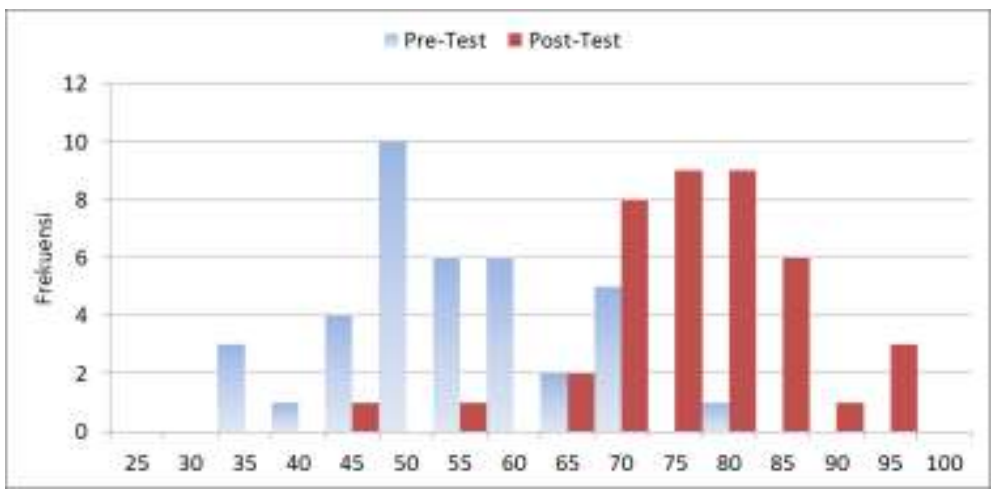

\section{Gambar 4. Grafik Distribusi Frekuensi Hasil Pre-Test dan Post-Test Pelatihan Penulisan Artikel Ilmiah di Pusdiklat BPS (Batch 1).}

Untuk Batch 2, nilai rata-rata kelas meningkat dari hanya 46.9 (median 45 dan SD \pm 11.92) pada saat pre-test menjadi 81.81 (median 80 dan SD \pm 9.09$)$ pada saat post-test. Nilai minimum dan maksimum pada saat pre-test adalah
25 dan 80 , sedangkan pada saat post-test adalah 55 dan 100. Hasil ini menunjukkan bahwa pengetahuan para peserta pelatihan Batch 2 pun meningkat, bahkan lebih baik daripada Batch 1 (Gambar 5).

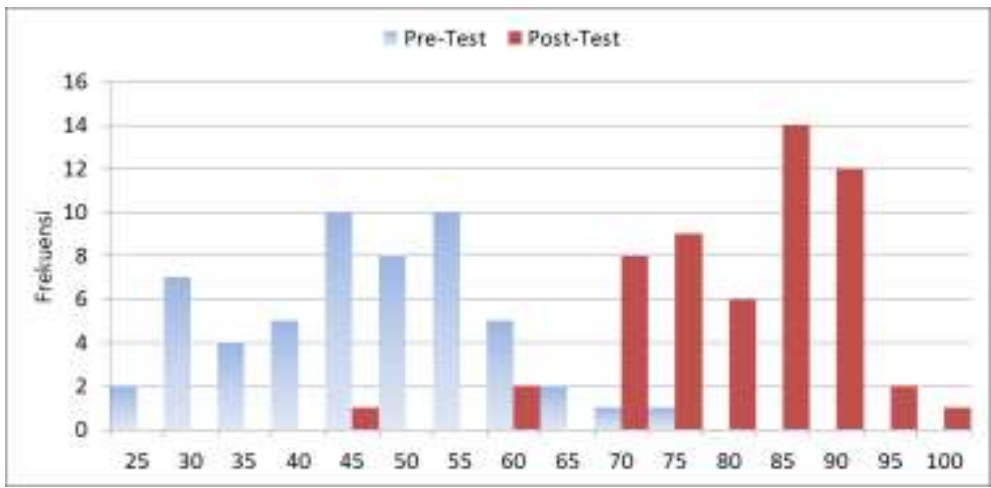

\section{Gambar 5. Grafik Distribusi Frekuensi Hasil Pre-Test dan Post-Test Pelatihan Penulisan Artikel Ilmiah di Pusdiklat BPS (Batch 2).}

\section{Peningkatan Kemampuan Praktis}

Dari hasil penerepan metode RT pada pelatihan penulisan artikel ilmiah di Pusdiklat BPS pada tahun 2018, dapat disimpulkan bahwa metode RT ini sangat efektif untuk meningkatkan kemampuan peserta dalam melakukan penulisan artikel ilmiah secara cepat dan produktif. Salah satu indikator keberhasilan tersebut adalah dari jumlah peserta yang berhasil melakukan paper submission ke jurnal ilmiah pada hari terakhir pelatihan. Padahal seluruh peserta memulai penyusunan artikel tersebut dari nol (scratch) dan dapat diselesaikan hanya dalam waktu empat hari pelatihan saja. Ini suatu capaian yang sangat menggembirakan, sebagai salah satu indikator keefektifan metode RT.

Pada Bacth 1, sebanyak 39 orang dari total 40 peserta pelatihan $(97.5 \%)$ berhasil melakukan paper submission pada hari terakhir pelatihan. Satu orang lainnya, berhasil melakukan paper 
submission tiga hari setelah yang bersangkutan kembali ke instansinya. Sedangkan pada Batch 2, seluruh peserta pelatihan yaitu sebanyak 55 orang
(100\%) berhasil melakukan paper submission pada hari terakhir pelatihan. Informasi tersebut dapat dilihat pada Tabel 4.

Tabel 4. Jumlah Peserta Pelatihan Yang Berhasil Melakukan Paper Submission Pada Hari Terakhir Pelatihan Dan Informasi Mengenai Level Jurnal Yang Dituju.

\begin{tabular}{ccc}
\hline $\begin{array}{c}\text { Level Akreditasi Jurnal Yang } \\
\text { Dituju } \\
\text { (sinta2.ristekdikti.go.id) }\end{array}$ & $\begin{array}{c}\text { Batch 1 } \\
\text { (orang) }\end{array}$ & $\begin{array}{c}\text { Batch 2 } \\
\text { (orang) }\end{array}$ \\
\hline Sinta 1 & - & - \\
Sinta 2 & 2 & 12 \\
Sinta 3 & 11 & 8 \\
Sinta 4 & 18 & 16 \\
Sinta 5 & 2 & 11 \\
Sinta 6 & 2 & 6 \\
Belum Akreditasi & 4 & 1 \\
Jurnal Luar Negeri & & 1 \\
\hline Jumlah Peserta & 39 & 55 \\
\hline
\end{tabular}

Setelah delapan bulan berlalu dari sejak pelaksanaan pelatihan penulisan artikel ilmiah di Pusdiklat BPS yang dilaksanakan pada bulan November 2018, telah banyak perkembangan yang menggembirakan mengenai status naskah-naskah artikel yang dikirimkan oleh para peserta pelatihan tersebut. Setiap ada komunikasi antara alumni dengan para editor jurnal tentang perbaikan artikel ataupun tentang perubahan status artikel, para alumni secara aktif menginformasikannya melalui fasilitas WAG.

Maka untuk mengetahui perkembangan (progress) terakhir dari naskah-naskah artikel tersebut, pada tanggal 1 September 2019 dibuatlah kuesioner evaluasi yang dikirimkan kepada seluruh alumni pelatihan baik Batch 1 maupun Batch 2. Dari total 95 orang alumni yang dikontak, 78 di antaranya (82\%) berhasil mengisi kembali kuesioner evaluasi tersebut dengan hasil yang sangat memuaskan.

Gambar 6 memperlihatkan kepada kita bahwa setelah delapan bulan sejak naskah artikel dikirimkan ke berbagai jurnal ilmiah, dari 95 peserta 32 artikel di antaranya $(33.7 \%)$ telah berhasil terbit. Selanjutnya 2 artikel (2.1\%) sudah dalam proses In Production dan 4 artikel (4.2\%) sudah dalam proses In Editing. Naskah-naskah yang sudah masuk proses In Production dan In Editing berarti naskah-naskah tersebut sudah diterima (accepted) oleh mitra bestari dan editor jurnal, tinggal menunggu periode penerbitan saja. Sementara itu, 13 artikel (13.9\%) masih dalam status In Review, artinya masih dalam tahap koreksi dan perbaikan.

Selain itu, 14 artikel (14.7\%) masih belum bergeser dari status Awaiting Assignment yang berarti sama sekali belum disentuh oleh editor jurnal. Selanjutnya, 11 artikel (11.6\%) telah mendapatkan penolakan dari editor, 6 responden (6.3\%) menyatakan tidak tahu status terakhir naskah KTI mereka, dan 13 peserta tidak mengisi kuesioner. 


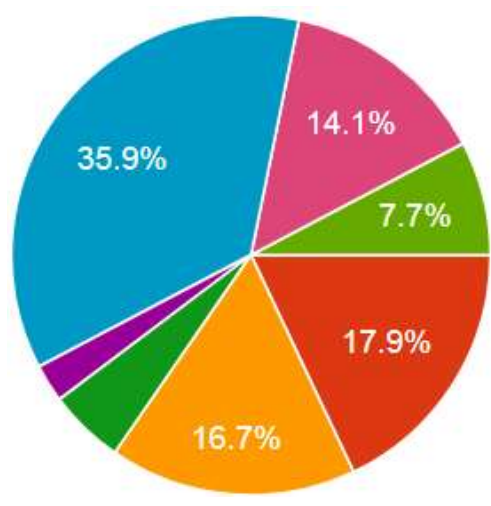

\author{
Keterangan: \\ Masih Awaiting Assignment \\ In Review \\ In Editing \\ In Production \\ Published (Sudah terbit) \\ Rejected (Ditolak) \\ Tidak Tahu
}

\title{
Gambar 6. Status Terakhir Naskah KTI Setelah Delapan Bulan Sejak Dikirimkan Ke Jurnal Ilmiah Oleh Para Alumni Pusdiklat BPS (gabungan Batch 1 dan Batch 2).
}

Melihat hasil di atas, dari 95 orang alumni pelatihan di Pusdiklat BPS (Batch 1 dan Batch 2), 32 artikel sudah berhasil terbit dan 6 artikel lainnya sedang menunggu proses terbit. Sehingga jika semuanya sudah benar-benar terbit, maka 38 artikel dari 95 orang alumni diklat (40\%) berhasil terbit pada jurnal ilmiah. Hal ini merupakan suatu capaian yang mengembirakan mengingat artikelartikel tersebut hanya disusun dalam waktu empat hari saja. Hal ini juga mengindikasikan efektifitas dan keberhasilan dari metode RT yang diimplementasikan dalam pelatihan penulisan artikel ilmiah ini. Tabel 5 merinci judul-judul artikel yang sudah terbit, termasuk nama penulis, nama jurnal, dan informasi lainnya.

Selanjutnya, sebagaimana dijelaskan di awal, untuk mengukur peningkatan kemampuan praktis (psikomotorik), peserta pelatihan diminta untuk mengisi kuesioner tentang pengukuran diri sendiri (self-assessment test) tentang seluruh praktik-praktik yang diajarkan selama pelatihan penulisan artikel ilmiah. Kuesioner tersebut terdiri dari 10 pertanyaan seputar praktik-praktik yang dilakukan oleh peserta dari mulai praktik mengolah data, praktik menuliskan hasil, sampai dengan praktik mengirimkan naskah artikel ke jurnal ilmiah.

Pada Batch1, hasil dari self-assessment test itu menunjukkan bahwa lebih dari $90 \%$ (mayoritas) peserta menyatakan bahwa mereka telah mampu menguasai teknik-teknik penulisan paper sampai mengirimkannya ke jurnal ilmiah dengan nilai berkisar antara cukup dan baik sekali. Hanya sebagian kecil saja dari peserta yang menyatakan bahwa mereka masih merasa kurang dalam beberapa hal. Ada tiga teknik yang masih dianggap kurang dikuasai oleh sekitar 10\% peserta, yaitu teknik mengutip referensi dan daftar pustaka, teknik menghindari plagiarisme, dan teknik pengiriman paper ke jurnal ilmiah.

Pada Batch2, hasil dari self-assessment test menunjukkan bahwa lebih dari 95\% (mayoritas) peserta menyatakan bahwa mereka telah mampu menguasai teknik-teknik penulisan paper sampai mengirimkannya ke jurnal ilmiah dengan nilai berkisar antara cukup dan baik sekali. Hanya sebagian kecil saja dari peserta yang menyatakan bahwa mereka masih merasa kurang dalam beberapa hal. Ada tiga teknik yang masih dianggap kurang dikuasai oleh sekitar 5\% peserta, yaitu teknik mengutip referensi dan daftar pustaka, teknik menghindari plagiarisme, dan teknik pengiriman paper (submission) ke jurnal ilmiah.

Akhirnya, hasil penelitian ini menyimpulkan bahwa pelatihan dengan praktik langsung, walaupun dilakukan dalam waktu singkat, namun dampaknya dapat memberikan kualitas yang jauh lebih baik dibandingkan dengan pelatihan yang hanya terfokus pada peningkatan kognitif belaka. Kesimpulan ini mendukung hasil penelitian yang telah dilakukan oleh Wischgoll (2017), Kellogg dan Whiteford (2009), Kellogg (2008); serta Kellogg dan Raulerson (2007). 
Tabel 5. Daftar Artikel Ilmiah Dari Peserta Pelatihan Penulisan Artikel Ilmiah Di Pusdiklat BPS Tahun 2018 Yang Telah Diterbitkan

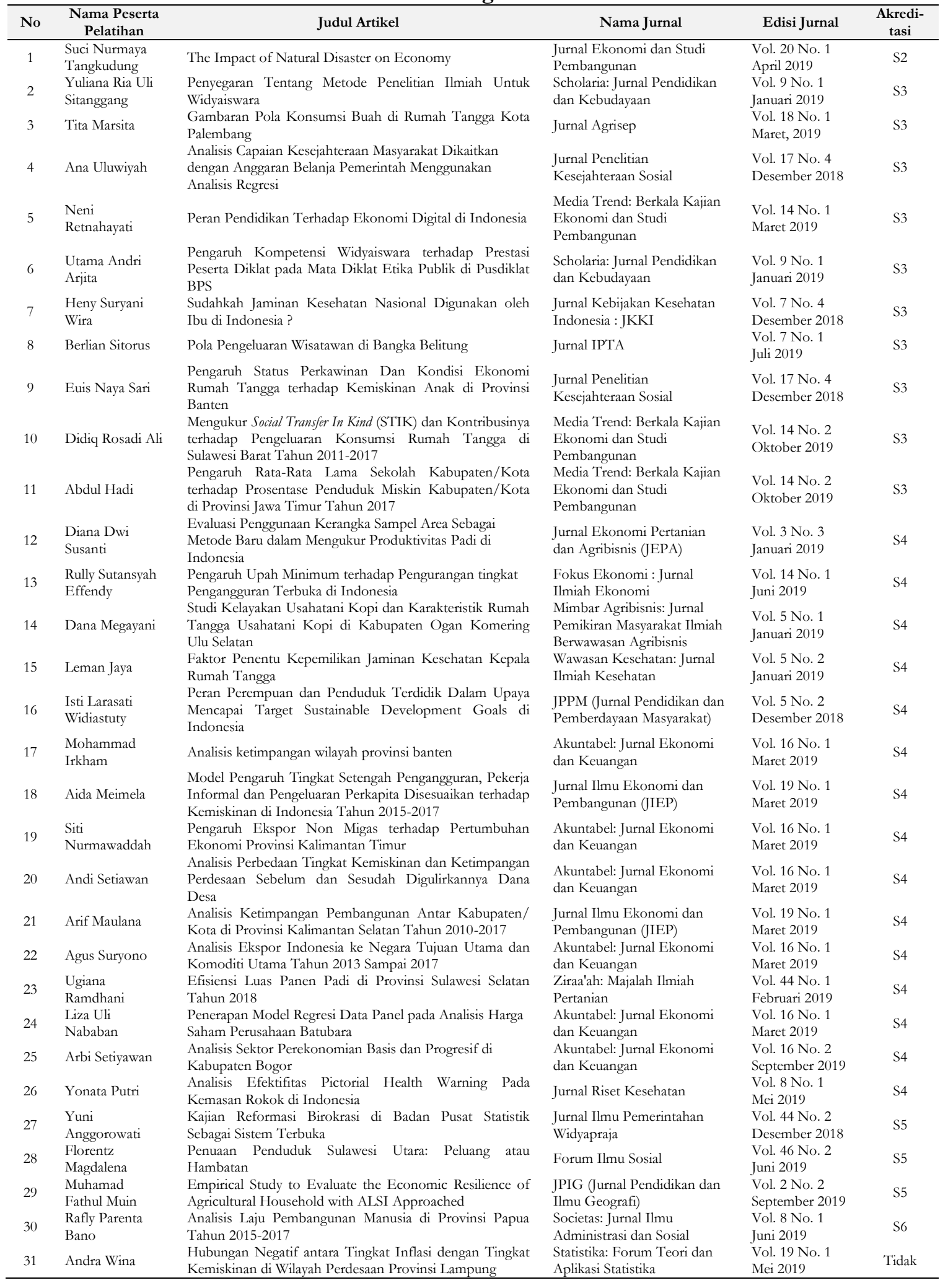




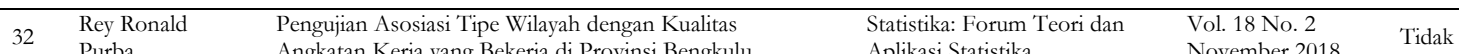

Sumber: Pengolahan data primer.

Teknik mencari masalah / topik dengan mengolah data

Teknik menulis hasil, pembahasan, dan kesimpulan

Teknik menulis metodologi dan pendahuluan

Teknik menulis judul dan abstrak

Teknik mengutip referensi dan daftar pustaka

Teknik menghindari plagiarisme

Teknik menyesuaikan dengan gaya selingkung

Teknik mencari jurnal ilmiah online

Teknik mencari referensi dari jurnal ilmiah online

Teknik melakukan submit paper ke jurnal ilmiah online

Keterangan Legend:

\section{0 \\ 0}

20

0
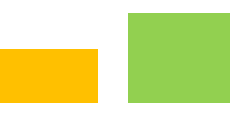

20

0
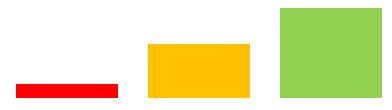

November 2018

Tidak
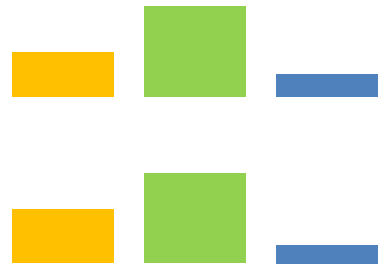

20
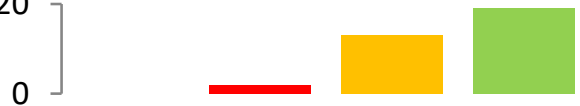

20

0
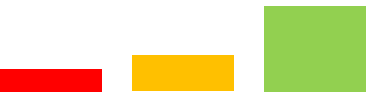

20

$\left.\begin{array}{l}20 \\ 0\end{array}\right]$
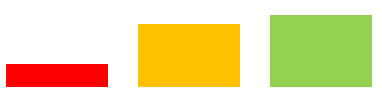

20
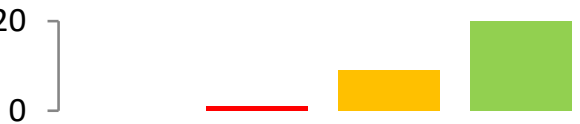

$\left.\begin{array}{c}20 \\ 0\end{array}\right]$
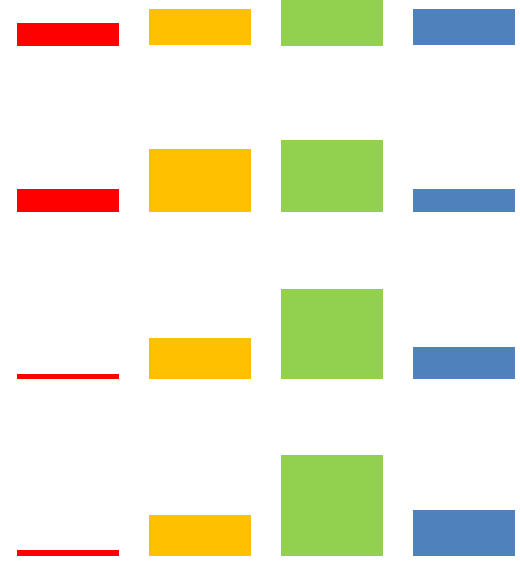

20
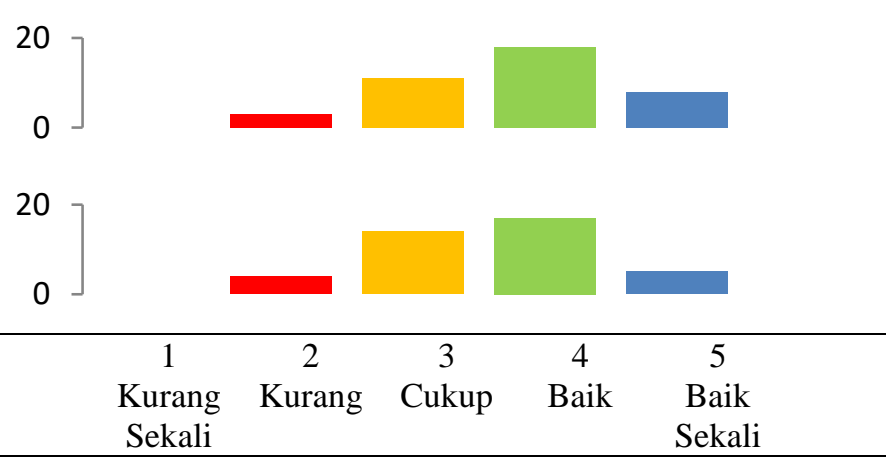

Gambar 7. Grafik Distribusi Frekuensi Self-Assessment Test Peserta Pelatihan Penulisan Artikel Ilmiah Di Pusdiklat BPS (Batch 1 Dan 2) Tentang Kemampuan Praktis (Psikomotorik) 


\section{Peningkatan Kemampuan Afekif}

Selain penguasaan materi, dari aspek afektif, peserta juga menyatakan sangat termotivasi untuk menulis lebih banyak paper dan mengolah data-data statistik yang selama ini tidak pernah mereka manfaatkan. Hal itu tergambar dari jawaban peserta yang diilustrasikan pada grafik skala Likert berskala 1 - 10 (Gambar 8), dengan jawaban yang terpusat antara nilai 7 dan 10 . Nilai ini meggambarkan peningkatan motivasi peserta pelatihan di antara memuaskan dan sangat memuaskan.

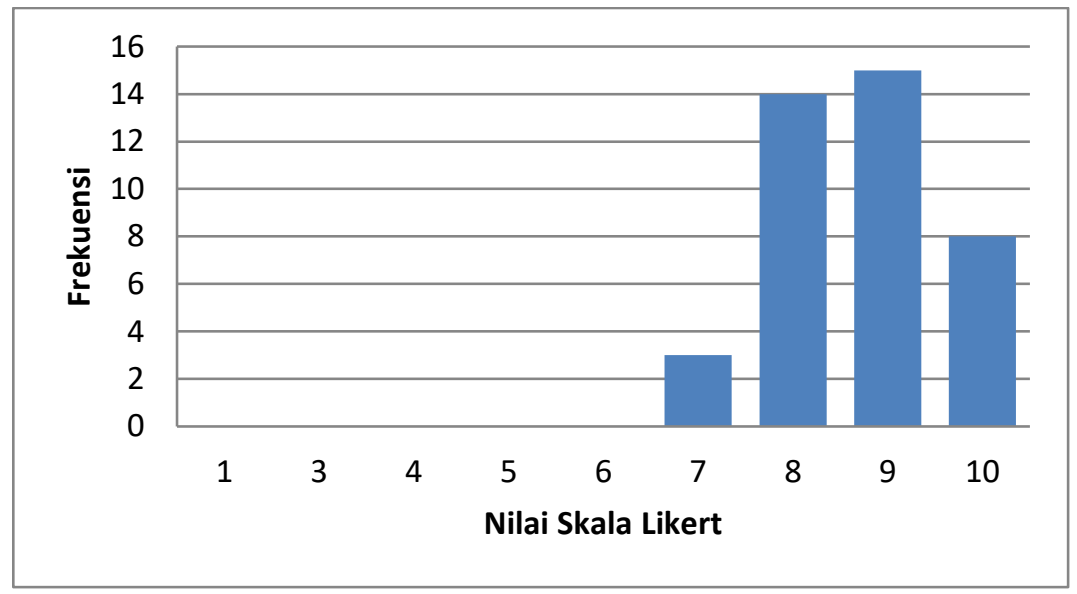

\section{Gambar 8. Grafik Skala Likert Distribusi Frekuensi Peningkatan Motivasi Peserta Pelatihan Penulisan Artikel Ilmiah Di Pusdiklat BPS Tahun 2018.}

\section{SIMPULAN DAN REKOMENDASI}

Kajian ini menyimpulkan bahwa:

1. Kajian ini berhasil mengembangkan sebuah inovasi metode pelatihan metode pelatihan yang disebut dengan metode berpikir terbalik (Reverse Thinking - RT) yang terdiri dari 17 tahapan penulis artikel ilmiah.

2. Hasil dari penerapan dan pengujian metode RT ini pada Pelatihan Penulisan Artikel Ilmiah di Pusdiklat BPS menunjukkan bahwa metode ini berhasil meningkatkan kemampuan peserta pelatihan yang diindikasikan dengan beberapa hal, yaitu: 1) Adanya peningkatan kemampuan kognitif peserta pelatihan yang dibuktikan dengan peningkatan nilai post-test yang signifikan dibandingkan dengan nilai pre-test;

\section{DAFTAR PUSTAKA}

Al-Omrani, K.A. (2014). Designing an effective training process: a case study at sohar development office Sutanate of Oman.
2) Hampir $100 \%$ peserta pelatihan mampu menyusun artikel ilmiah dari nol (scratch) hanya dalam waktu empat hari pelatihan dan berhasil mengirimkan naskah artikel tersebut ke jurnal-jurnal ilmiah; 3) Setelah delapan bulan sejak pelatihan berlalu, terdapat 32 peserta pelatihan dari total 95 peserta pelatihan (33.7\%) yang artikelnya berhasil diterbitkan pada jurnal-jurnal ilmiah nasional, dan 6 artikel lainnya $(6.3 \%)$ sudah dinyatakan diterima oleh jurnal dan sedang menunggu periode terbit; 4) Terdapat peningkatan nilai afektif (motivasi) peserta pelatihan dalam melakukan penulisan artikel ilmiah dengan nilai terpusat antara 7 dan 10 dari skala Likert $1-10$.

Disertasi Doktor. Graduate School of Government. College of Law, Government 
Jurnal PAJAR (Pendidikan dan Pengajaran)

Volume 4 Nomor 4 Juli 2020 | ISSN Cetak : 2580 - 8435 | ISSN Online : 2614 - 1337

DOI : http://dx.doi.org/10.33578/pjr.v4i2.7947

and International Studies, Universiti Utara Malaysia. 248p.

Ananta, H., Murnomo, A., Kartono, R., \& Mulwinda, A. (2016). Pelatihan dan pendampingan penulisan artikel ilmiah untuk e-journal mahasiswa Jurusan Teknik Elektro FT Unnes. Rekayasa: Jurnal Penerapan Teknologi dan Pembelajaran, 14(2), 121-125.

Arden, P. (2006). Whatever you think, think the opposite. Portfolio. $142 \mathrm{p}$.

Arta, K.S. (2018). Pelatihan penulisan artikel untuk publikasi di jurnal ilmiah untuk meningkatkan profesionalisme bagi guruguru di Kecamatan Kubutambahan Kabupaten Buleleng. Prosiding Seminar Nasional Hukum dan Ilmu Sosial ke-2, 146-159.

Arthur, R. (2018). Evaluasi program diklat karya tulis ilmiah untuk widyaiswara Pusbangtendik Kemendikbud. Jurnal Penelitian dan Evaluasi Pendidikan, 22(1), 35-48.

Batubara, H.H., \& Ariani, D.N. (2016). Workshop penggunaan Google Form sebagai media evaluasi pembelajaran pada dosenkhadosen fakultas studi Islam. Jurnal AlIkhlas, 2(1), 39-44.

Covey, S. (1989). The 7 habits of highly effective people. Free Press. 381 p.

Elfindri, Rustad, S., Nizam, \& Dahrulsyah. (2015). Lecturer performances in Indonesia higher education system. International E-journal of Advances in Education, 1(1), 26-36.

English Language \& Usage. (2018, November, 29).

https://english.stackexchange.com/questio ns/226886/origin-of-i-hear-and-i-forget-i-

see-and-i-remember-i-do-and-i-understand

Farmer, R., Oakman, P., \& Rice, P. (2016). A review of free online survey tools for undergraduate students. MSOR Connections, 15(1), 71-78.

Ginanjar, A. (2018). Peningkatan mutu karya tulis dosen fis dengan menggunakan reference manager software Mendeley. Harmony: Jurnal Pembelajaran IPS dan PKN, 3(2), 199-203.
Gutiérrez, D. C., \& Villegas. E. G. (2015). The importance of methodology in heigher education: a critical look. Procedia Social and Behavioral Sciences, 174, $377-$ 382.

Hajjar, S.T.E.L., \& Alkhanaizi, M.S. (2018). Exploring the factors that affect employee training effectiveness: a case study in Bahrain. SAGE Open, 1-12.

Hoogenboom, B.J. and Manske, R.C. (2012). How to write a scientific arcticle. International of sports physical therapy, 7(5), 512-517.

Indarti, S. (2012). Inovasi metode pembelajaran mata kuliah metode penelitian manajemen dengan metode konstruktivisme dalam rangka menurunkan durasi studi mahasiswa (Studi kasus Jurusan Manajemen Fakultas Ekonomi Universitas Riau). Jurnal Ekonomi, 20(4), 1-18.

Jenkins, S. (1995). How to write a paper for a scientific journal. Australian Journal of Physiotherapy, 41(4), 285-289.

Kellogg, R. T. (2008). Training writing skills: A cognitive developmental perspective. Journal of Writing Research, 1, 1-26.

Kellogg, R. T., \& Raulerson, B. A. (2007). Improving the writing skills of college students. Psychonomic Bulletin \& Review, 14, 237-242

Kellogg, R. T., and Whiteford, A. P. (2009). Training advanced writing skills: The case for deliberate practice. Education Psychology. 44, 250-266

Khales, B. (2016). The impact of a teacher training program on mathematics teaching methodologies: using student-centered learning. American Journal of Educational Research, 4(14), 992-998.

Kremer, L., \& Perlberg, A. (2006). Training of teachers in strategies that develop independent learning skills in their pupils. British Journal of Teacher Education, 5(1), 35-47. https://doi.org/10.1080/026074779005010 $\underline{4}$.

Lim, D.H. (2000). Training design factors influencing transfer of training to the workplace within an international context. 
Jurnal PAJAR (Pendidikan dan Pengajaran)

Volume 4 Nomor 4 Juli 2020 | ISSN Cetak : 2580 - 8435 | ISSN Online : 2614 - 1337

DOI : http://dx.doi.org/10.33578/pir.v4i2.7947

Journal of Vocational Education \& Training, 52(2), 243-258.

Madjid, S., Emzir, \& Akhadiah, S. (2017). Improving academic writing skills through contextual teaching learning for students of Bosowa University Makassar. Journal of Education, Teaching and Learning, 2(2), 268-272.

Punia, B.K., \& Kant, S. (2013). A review of factors affecting training effectiveness visà-vis managerial implications and future research directions. International Journal of Advanced Research in Management and Social Sciences, 2(1), 151-164.

Rahmiati. (2015). Analisis kendala internal mahasiswa dalam menulis karya ilmiah. Al-Daula, 4(2), 327-343.

Redhana, I.W., Kirna, I.M., Suardana, I.N., \& Subagia, I.W. (2016). Pelatihan penulisan artikel ilmiah bagi guru-guru kimia di Kabupaten Buleleng. Widya Laksana: Jurnal Pengabdian Kepada Masyarakat, $3(2), 20-33$.

Rohaeni, N., \& Jubaedah, Y. (2010). Model disain kurikulum pelatihan profesi guru vokasional berbasis technological curriculum. Jurnal Penelitian Pendidikan, 11(2), 41-53.

Salamah, U., \& Sumarsilah, S. (2018). Pembelajaran menulis karya ilmiah berbasis Deep Dialogue Critical-Creative Thinking (DDCT). Jurnal Inovasi Pembelajaran, 4(1), 90-101.

Slamet, J. (2016). Otak-atik Google Form guna pembuatan kuesioner kepuasan pemustaka. Info Persadha, 14(1), 21-35.

Swanson, R.A., \& Holton, E.F. (2001). Foundations of human resource development. Berrett-Koehler Publishers, Inc., San Fransisco - California. 439p.

Velada, R., Caetano, A., Michel, J.W., Lyons, B.D,, \& Kavanangh, M.J. (2007). The effects of training design, individual characteristics and work environment on transfer of training. International Journal of Training and Development, 11(4), 282294.

Wiryawan, K.G. (2014). The current status of science journals in Indonesia. Science Editing, 1(2), 71-75.

Wischgoll, A. (2017). Improving undergraduates' and postgraduates' academic writing skills with strategy training and feedback. Frontiers in Education, 2(33), 1-15. doi: 10.3389/feduc.2017.00033

Yaqoot, E.S.I., Noor, W.S.W.M., \& Isa, M.F.M. (2017). Factors influencing training effectiveness: evidence from public sector in Bahrain. Acta Universitatis Danubius: Economica, 13(2), 31-44.

https://risbang.ristekdikti.go.id/publikasi/beritamedia/salip-singapura-publikasi-ilmiahindonesia-peringkat-2-asean/

https://mediaindonesia.com/read/detail/158754kualitas-publikasi-ilmiah-penelitiindonesia-masih-rendah 